\title{
A TRAVÉS DE LA BRUMA... \\ LAS POBLACIONES EN SITUACIÓN DE VULNERABILIDAD SOCIAL EN LAS FUENTES DE DATOS SOCIODEMOGRÁFICAS DE LA ARGENTINA (1994-2015)
}

\author{
Bruno S. Ribotta* \\ María Marta Santillán Pizarro** \\ Leandro M. González ***
}

Resumen. Las mujeres, las niñas y los niños, los migrantes, los refugiados, los pueblos indígenas y los afrodescendientes, son algunas de las poblaciones en situación de vulnerabilidad social que viven en Argentina. El goce y ejercicio efectivo de sus derechos humanos pueden verse limitados por este motivo, aun cuando estos constituyen atributos inherentes a la dignidad humana y poseen protección jurídica universal. La recolección de datos estadísticos producidos por los Estados, de manera sistemática, desagregada y acorde a los estándares de calidad y confiabilidad, es reconocida por organismos de Naciones Unidas como una herramienta fundamental para la identificación de estas poblaciones en situación de vulnerabilidad social. En este contexto, el objetivo principal del trabajo es diagnosticar la situación de la Argentina en relación a la disponibilidad de las fuentes de información sociodemográfica, elaboradas oficialmente desde 1994 a 2015, para la visibilización de las poblaciones en situación de vulnerabilidad social. Entre las principales conclusiones, se destaca que estas poblaciones no pueden ser identificadas en todos los casos (particularmente las personas afrodescendientes, las pertenecientes a pueblos indígenas y los refugiados). Por lo tanto, es importante invertir en el rediseño de las fuentes de datos (lo que implica la inclusión de nuevas variables o la reformulación de sus preguntas) y/o el desarrollo de nuevas fuentes de datos, más específicas.

Palabras Clave: Fuentes de datos sociodemográficos; Vulnerabilidad social; Derechos humanos.

\footnotetext{
* Centro de Investigaciones y Estudios sobre Cultura y Sociedad (CIECS), Consejo de Investigaciones Científicas y Técnicas (CONICET, Argentina) y Universidad Nacional de Córdoba (UNC, Argentina).

Contacto: brunoribo@yahoo.com.ar

${ }^{* *}$ Centro de Investigaciones y Estudios sobre Cultura y Sociedad (CIECS), Consejo de Investigaciones Científicas y Técnicas (CONICET, Argentina) y Universidad Nacional de Córdoba (UNC, Argentina).

Contacto: mm_santillan@yahoo.com.ar

*** Centro de Investigaciones y Estudios sobre Cultura y Sociedad (CIECS), Consejo de Investigaciones Científicas y Técnicas (CONICET, Argentina) y Universidad Nacional de Córdoba (UNC, Argentina).
}

Contacto: leandrogonzalez@yahoo.com.ar 


\title{
THROUGH THE FOG... \\ POPULATIONS IN SOCIAL VULNERABILITY SITUATIONS IN ARGENTINA'S SOCIO-DEMOGRÁPHIC DATA SOURCES
}

(1994-2015)

\begin{abstract}
Women, girls and boys, migrants, refugees, indigenous peoples and afrodescent are some of the most socially vulnerable populations living in Argentina. Their human rights may be limited, even though those rights are inherent attributes to human dignity and they have universal legal protection. Different United Nations agencies recognize, as a meaningful tool, the production of reliable, systematic and disaggregated statistical information that show up such situations of social vulnerability. In this context, the aim of the article is to diagnose the Argentinian situation in relation to the availability of socio-demographic information sources, officially prepared from 1994 to 2015, for the visibility of populations in social vulnerability situations. Among the main conclusions, we highlight that these populations cannot be identified in all cases (particularly African descent, indigenous peoples and refugees). Thus, it is important to invest in the redesign of data sources (which implies the inclusion of new variables or the reformulation of their questions ) and/or development of new more specific sources of data.
\end{abstract}

Keyword: Sociodemographic Data Sources; Social Vulnerability; Human Rights.

Original recibido el 03/05/2018

Aceptado para su publicación el 27/12/2019 


\section{Introducción}

Los derechos humanos son inherentes a todas las personas, sin distinción por sexo, origen nacional o étnico, color, lugar de residencia u otra característica. Es decir que todos los seres humanos tienen los mismos derechos, sin discriminación alguna.

Los derechos humanos también involucran obligaciones personales y colectivas. Al nivel individual, así como deben hacerse respetar los derechos humanos que competen a cada uno, deben respetarse los derechos de los demás. Al nivel colectivo, los Estados poseen obligaciones y los deberes, sustentados por el derecho internacional, de respetar, proteger y realizar los derechos humanos de los habitantes de su respectivo país. Con relación a la obligación de respetar, los Estados deben abstenerse de interferir o limitar el disfrute de los derechos humanos. La obligación de protegerlos significa que los Estados deben impedir los abusos contra los derechos humanos de individuos y grupos. Finalmente, tienen la obligación de adoptar medidas positivas para facilitar el disfrute de los derechos humanos básicos, es decir, para realizarlos (Alto Comisionado de las Naciones Unidas para los Derechos Humanos [ACNUDH, o OHCHR por sus siglas en inglés], 2015).

En Argentina, muchos de los tratados internacionales sobre derechos humanos poseen jerarquía constitucional desde 1994, por lo que cuentan con el imperativo legal de mayor jerarquía jurídica para el Estado ${ }^{1}$. Además, el país asume otros compromisos que, si bien no presentan esta característica, refieren a acuerdos intergubernamentales que, basándose en los contenidos de dichos tratados, fijan líneas de acción y prioridades de las agendas de desarrollo de los países. Tal es el caso de los Objetivos de Desarrollo Sostenible (ODS) de la Agenda 2030 a nivel mundial y el Consenso de Montevideo sobre Población y Desarrollo a nivel regional. Más allá del reconocimiento y compromiso existente, el goce y ejercicio efectivo de los derechos fundamentales y la posibilidad de acceder a la justicia pueden verse limitados por pertenecer a una población en situación de vulnerabilidad social. Este concepto ha sido objeto de diversas definiciones a lo largo del tiempo, y varía también según el ámbito temático al que se refiere. En los países más desarrollados y con relación a estudios ambientales, desde los años ochenta la vulnerabilidad social ha sido entendida como el grado de exposición de un conjunto de personas a sufrir daños a causa de eventos catastróficos (Cutter, 1996). Desde una perspectiva más sociológica y situada en la crisis del empleo tradicional en los años noventa, Castel identificó a la vulnerabilidad como una "zona" generada por la precariedad de las relaciones de trabajo y la fragilidad de los vínculos sociales, que conducen a la desafiliación de quienes la habitan (Castel, 1997).

A fines de los años noventa en América Latina se identificó a la vulnerabilidad social con características de las personas, hogares y comunidades que las incapacitaban para mejorar su bienestar o enfrentar coyunturas económicas desfavorables (Busso, 2001; CEPAL [Comisión Económica para América Latina y el Caribe], 2001; Kaztman, 1999). Desde este punto de vista las personas están expuestas a eventos sociales

1 Cada tratado fue aprobado en diferentes momentos, con sus leyes respectivas. La Reforma Constitucional de 1994 jerarquizó dichos tratados, de manera que no pudieran ser derogados por otra ley del Congreso sino únicamente por una nueva reforma constitucional. 
adversos, es decir a "riesgos", por sus propias condiciones y por el desempeño que pueden realizar en el medio en donde viven.

Para reforzar el carácter dinámico del concepto y evitar la estigmatización de las personas, a fines de la década de 2000 se propuso utilizar la expresión de personas/ poblaciones en situación de vulnerabilidad que son:

aquellas que, por razón de edad, género, estado físico o mental, o circunstancias sociales, económicas, étnicas y/o culturales encuentran dificultades para ejercer con plenitud sus derechos. Podrán constituir causas de vulnerabilidad, entre otras, la edad, la discapacidad, la pertenencia a comunidades indígenas o a minorías, la victimización, la migración y el desplazamiento interno, la pobreza, el género y la privación de libertad (XIV Cumbre Judicial Iberoamericana, 2008, pág. 5).

Con base a este giro terminológico-conceptual, se puede afirmar que la vulnerabilidad social quebranta y disuelve garantías y libertades fundamentales. Los derechos de las personas en situación de vulnerabilidad social se detentan a nivel formal, pero no en los hechos.

En torno a esta constatación, los organismos de Naciones Unidas aúnan esfuerzos con los Estados para velar por los compromisos asumidos por éstos. Como expresión sobresaliente de este interés, se considera como herramienta indispensable la información estadística confiable y sistemática. También se construyen marcos conceptuales y metodológicos que establecen indicadores pertinentes (ACNUDH, 2008).

Uno de los principios que se siguen para la construcción de indicadores cuantitativos para medir los avances en materia de derechos humanos, es visibilizar la situación de personas en situación de vulnerabilidad (ONU [Organización de las Naciones Unidas], 2006; citada por Ferrer, 2007). Asimismo, en el marco de las Conferencias Internacionales, los Objetivos de Desarrollo Sostenible (ODS), mediante la meta 17.18 también señalan la necesidad de disponer de datos desglosados por múltiples características de la población, que sean oportunos, fiables y de gran calidad:

Para 2020, mejorar la prestación de apoyo para el fomento de la capacidad a los países en desarrollo, incluidos los países menos adelantados y los pequeños Estados insulares en desarrollo, con miras a aumentar de forma significativa la disponibilidad de datos oportunos, fiables y de alta calidad desglosados por grupos de ingresos, género, edad, raza, origen étnico, condición migratoria, discapacidad, ubicación geográfica y otras características pertinentes en los contextos nacionales (ONU, 2015)².

Aquí se debe advertir que, si bien la información estadística puede identificar grupos en situación de vulnerabilidad social, pueden presentarse limitaciones para evaluar el grado de cumplimiento de los derechos invocados. Al respecto advierten Pemberton, Gordon y Nandy (2012, pág. 31) que el vínculo entre derechos e indicadores de cumplimiento depende de cuán específicos son los deberes que contienen esos derechos; cuanto más precisa es la prescripción del derecho, mayor es la probabilidad de encontrar un indicador de cumplimiento eficaz, como en el caso del acceso a la educación. Los autores consideran que hay un rango de tipo continuo entre "deberes perfectos/indicadores directos" y "deberes imperfectos/indicadores

2 https://www.un.org/sustainabledevelopment/es/globalpartnerships/ 
indirectos". Cuando los artículos de las convenciones de derechos son más ambiguos (por ejemplo "combatir las enfermedades y la malnutrición"), los indicadores son más difíciles de interpretar y se requieren de grupos de indicadores para abarcar todas las interpretaciones posibles de estos derechos.

En este contexto, nos preguntamos por las capacidades estadísticas en la Argentina para visibilizar las poblaciones en situación de vulnerabilidad social. En otras palabras, ¿con qué fuentes de datos socio-demográficos oficiales cuenta el país para realizar el monitoreo del cumplimiento de los derechos humanos? ¿Cuáles son las posibilidades que ofrecen estas fuentes para identificar las poblaciones en situación de vulnerabilidad social mediante preguntas/variables pertinentes, necesarias para que sea posible definir políticas públicas focalizadas y evaluar el ejercicio de sus derechos?

De esta manera el objetivo principal del trabajo es diagnosticar la realidad de la Argentina con relación a la disponibilidad de las fuentes de información sociodemográfica, elaboradas oficialmente desde 1994 a 2015, para la visibilización/ identificación de las poblaciones en situación de vulnerabilidad social.

\section{Metodología y fuentes de datos}

Se comentan a continuación los procedimientos que se utilizan para diagnosticar la disponibilidad de fuentes de datos oficiales, que permitan identificar las poblaciones en situación de vulnerabilidad social:

\subsection{Principales dimensiones y variables que definen a las poblaciones en situación de vulnerabilidad social}

Considerando los criterios asociados corrientemente a las causas de vulnerabilidad social, se seleccionan las siguientes poblaciones: niños y niñas, mujeres, personas adultas mayores, pueblos indígenas, afrodescendientes, migrantes, y refugiados, y se revisan las principales herramientas de derecho internacional impulsadas por Naciones Unidas, que más relevancia poseen para los Estados en términos vinculantes, con relación al ejercicio de derechos de grupos poblacionales específicos (ACNUDH, 2017).

El listado de poblaciones en situación de vulnerabilidad social no es exhaustivo, pero sí responde a poblaciones contempladas explícitamente enla Convención sobre el Estatuto de los Refugiados (ONU, 1951), la Convención Internacional sobre la Eliminación de todas las Formas de Discriminación Racial (ONU, 1966), la Convención sobre la eliminación de todas las formas de discriminación contra la mujer (ONU, 1979), la Convención sobre los Derechos del Niño (ONU, 1989), la Convención Internacional sobre la protección de los derechos de todos los trabajadores migratorios y de sus familiares (ONU, 1990), la Convención sobre los derechos de las Personas con Discapacidad (ONU, 2006) y Convención Interamericana sobre la Protección de los Derechos Humanos de las Personas Mayores.

A partir de la selección de poblaciones en situación de vulnerabilidad social, se identifica su definición teórica, de carácter oficial, y dentro de ésta, cuáles son las variables a partir de las cuales se delimitan (edad, sexo, lugar de residencia, etc). Dichas variables serán buscadas posteriormente en los cuestionarios de las fuentes de información. 


\subsection{Búsqueda de fuentes de datos de alcance sociodemográfico producidas en las dos últimas décadas, sus metadatos y notas técnicas, y revisión documental sobre sus resultados.}

Entre las fuentes de datos socio-demográficas, se selecciona exclusivamente a las producidas oficialmente en la Argentina durante las últimas dos décadas (1994-2015). Se considera dicha instancia temporal para incluir a todos aquellos relevamientos realizados desde que las principales convenciones de Naciones Unidas adquieren jerarquía Constitucional (República Argentina ([1994] 2010), Artículo 22), hasta el año 2015 inclusive, punto de inicio de la medición de los ODS. Interesa analizar la situación en las dos décadas entendidas como una primera etapa, con vistas a la medición futura de los avances en este aspecto.

De ese conjunto, se analizan sólo las fuentes de datos diseñadas y producidas por el Instituto Nacional de Estadísticas y Censos de la Argentina (INDEC), de manera exclusiva o en colaboración con otros organismos del Estado. Se excluyen a las fuentes de datos generadas de manera sectorial, que hayan sido delegadas operativamente por el INDEC a otros organismos (como las Estadísticas Vitales, actualmente a cargo de la Dirección de Estadísticas e Información en Salud [DEIS]) o que se elaboren sin su mediación directa (como los Relevamientos Anuales de Educación de la Dirección Nacional de Información y Estadística Educativa [DiNIECE]). En este sentido, se analizan dos tipos de fuentes de información sociodemográfica; los censos de población y vivienda y las encuestas de hogar y de temáticas específicas.

Debido a que se pretende reconocer si dichas fuentes de datos permiten identificar poblaciones en situación de vulnerabilidad social, en esta selección de fuentes se incluyen los relevamientos cuya unidad de análisis es el individuo. No se consideran relevamientos que difieran este este aspecto, con otras unidades de análisis (hogar, las unidades de explotación, etc.). Por ejemplo, la Encuesta Nacional de Gasto de los Hogares (ENGH 1996-1997 y 2004-2005, ENGHo 2011-2012).

El listado completo de las fuentes se incluye a continuación:

- Censo Nacional de Población, Hogares y Viviendas de 2001 (C2001), relevamientos de hogares particulares y de instituciones colectivas.

- Encuesta Nacional de Personas con Discapacidad (ENDI), 2002-2003. Encuestas Complementarias del Censo Nacional de Población, Hogares y Viviendas de 2001.

- Encuesta Complementaria de Pueblos Indígenas (ECPI), 2004-2005. Encuestas Complementarias del Censo Nacional de Población, Hogares y Vivienda de 2001.

- Encuesta Complementaria de Migraciones Internacionales (ECMI), 20022003. Encuestas Complementarias del Censo Nacional de Población, Hogares y Viviendas de 2001.

- Censo Nacional de Población, Hogares y Viviendas 2010 (C2010), relevamiento básico, ampliado y de viviendas colectivas.

- Encuesta de Desarrollo Social (EDS), 1997.

- Encuesta Condiciones de Vida (ECV), 2001. 
- Encuesta Nacional de Factores de Riesgo (ENFR), de 2005, 2009 y 2013.

- Encuesta Nacional sobre Calidad de Vida de los Adultos Mayores (ENCaViAM), 2012.

- Encuesta Nacional de Personas con Discapacidad (ENDI), 2002-2003.

- Encuesta Permanente de Hogares (EPH, puntual), hasta 2002/2003.

- Módulo para el Monitoreo de Metas Sociales, EPH (puntual), 1994.

- Encuesta Permanente de Hogares (EPH, continua), desde 2002/2003.

- Encuesta Anual de Hogares Urbanos (EAHU), desde 2010.

- Módulo de Actividades de Niños, Niñas y Adolescentes (MANNyA), de 2004, $2006(\mathrm{EPH})$ y de 2012 (AEHU).

- Encuesta Nacional sobre Prevalencias de Consumo de Sustancias Psicoactivas (ENPreCoSP), 2008 y 2011.

- Encuesta Nacional sobre Acceso y Uso de Tecnologías de la Información y la Comunicación (ENTIC), 2011 y 2015.

- Encuesta sobre Trabajo No Remunerado y Uso del Tiempo (módulo EAHU), 2013.

- Encuesta Nacional sobre Salud Sexual y Reproductiva (ENSSyR), 2013.

- Encuesta Nacional de Protección y Seguridad Social (ENAPROSS), 2011 y 2014-2015.

- Encuesta Mundial de Tabaquismo en Adultos (EMTA/GATS), 2012.

\subsection{Sistematización y análisis de cuestionarios y metadatos}

Finalmente, y como fuera anticipado, se procede a identificar las variables involucradas en la conceptualización de las poblaciones en situación de vulnerabilidad social que fueron seleccionadas, en los cuestionarios de las fuentes de datos (Tabla 1). A continuación, se analizan los metadatos de dichos relevamientos, para determinar el tipo de fuente, periodicidad, cobertura geográfica, dominios de estimación y posibilidades de desagregación geográfica (Tabla 2$)^{3}$.

\section{Resultados}

\subsection{Definiciones conceptuales}

A continuación, se detallan las definiciones conceptuales de cada una de las poblaciones en situación de vulnerabilidad social seleccionadas, según constan en Convenciones y Normas de la Organización de las Naciones Unidas. Con base a dichas definiciones, se reconocen a las variables involucradas, y a partir de ellas, se operacionaliza el concepto en las fuentes de datos (es decir, que se diagnostica su presencia en los cuestionarios respectivos).

\subsubsection{Niños y niñas}

La Convención sobre los Derechos del Niño, define como tal a toda persona entre 0 y 17 años (ONU, 1989). Como puede apreciarse, la variable a partir de la cual se realiza la definición es la edad cumplida.

\footnotetext{
3 A futuro se espera ampliar la identificación de las variables que permitan la caracterización de aspectos específicos de las condiciones de vida, y complementar el análisis de las desagregaciones geográficas con el cálculo de los porcentajes de datos ignorados o mal definidos, para estudiar la exactitud de la información correspondiente.
} 
Asimismo, y como el rango utilizado es muy amplio, a partir de la definición suelen establecerse clasificaciones internas. Por ejemplo, es corriente que se hable de primera infancia, infancia intermedia, adolescencia, juventud y personas jóvenes. Con relación a la primera de estas categorías, como menciona SITEAL [Sistema de Información de Tendencias Educativas en América Latina]:

Las concepciones y los enfoques de la primera infancia varían de acuerdo con el país y la región según las distintas tradiciones, las formas de organización familiar y de acuerdo con el modo en el que están estructurados los sistemas de enseñanza primaria. La definición que logró el mayor consenso en el nivel internacional es la que adoptan el Fondo de las Naciones Unidas para la Infancia (UNICEF) y el Comité de los Derechos del Niño. Esta definición establece que la primera infancia constituye el período que transcurre 'desde el nacimiento, el primer año de vida, el período pre-escolar hasta la transición hacia el período escolar'. En términos operacionales toma el tramo que abarca desde el nacimiento hasta los ocho años de edad (SITEAL, 2010, pág. 13).

Consecuentemente, se podría hablar de "segunda infancia" o "infancia intermedia" entre los 6-8 años y los 10 o los 15 años (dependiendo de si el límite de edad se fija a partir de la adolescencia o la juventud). Con relación a la definición de adolescentes y jóvenes, también incluidos totalmente en el rango de edad indicativo de la niñez según la Convención sobre los Derechos del Niño, existen algunas variantes que pueden identificarse en la práctica:

UNICEF y sus aliados como el Fondo de Población de Naciones Unidas (UNFPA), la Organización Mundial de la Salud (OMS) y el Programa Conjunto de las Naciones Unidas sobre el VIH/Sida (ONUSIDA), definen como "Adolescentes" a las personas entre 10 y 19 años. La Asamblea General de las Naciones Unidas define como "joven" a todas las personas entre los 15 y los 24 años de edad, y "personas jóvenes" a aquellos que tienen entre 10 y 24 años. Estas definiciones se aprobaron durante el Año Internacional de la Juventud en 1985 y han sido utilizadas por los organismos de las Naciones Unidas y otros aliados. En general, se reconoce la utilización superpuesta de estas definiciones, y "adolescente" y "joven" se utilizan de manera indistinta con "persona joven". Además de estas definiciones aprobadas por las Naciones Unidas y sus organismos, cada gobierno nacional tiene su propia definición y edad límite para los niños, los adolescentes, las personas jóvenes y los jóvenes (UNICEF, 2011, pág. 78).

\subsubsection{Mujeres}

La Convención sobre la Eliminación de Todas las Formas de Discriminación contra la Mujer (Naciones Unidas, 1979) consta de 30 artículos sobre la discriminación contra las mujeres, y establece una serie de mecanismos para terminar con la misma. Conceptualmente, la Convención se centra en la cultura y la tradición como fuerzas influyentes que dan forma a los roles de género y a las relaciones familiares. Para operacionalizar dicha visión, la variable ha correspondido tradicionalmente al sexo. Como destaca la Entidad de la ONU para la Igualdad de Género y el Empoderamiento de la Mujer (ONU Mujeres), los datos desagregados por sexo:

Son datos a los que se aplica la clasificación cruzada por sexo y así presentan información separada para hombres y mujeres, niños y niñas. Los datos desagregados por sexo reflejan los roles, situaciones reales, condiciones generales de hombres y mujeres, 
niñas y niños en cada aspecto de la sociedad. Por ejemplo, la tasa de alfabetización, nivel educativo, propiedad de negocios, empleo, diferencias salariales, dependientes, propiedad de la vivienda y la tierra, préstamos y créditos, deudas, etc. Cuando los datos no están desagregados por sexo, es más difícil identificar las desigualdades reales y potenciales. Los datos desagregados por sexo son necesarios para un análisis de género eficaz" (ONU Mujeres, 2017, pág. 9).

\subsubsection{Personas mayores}

La Convención Interamericana sobre derechos de las Personas Adultas Mayores ${ }^{4}$, se propone:

Promover, proteger y asegurar el reconocimiento y el pleno goce y ejercicio, en condiciones de igualdad, de todos los derechos humanos y libertades fundamentales de la persona mayor, a fin de contribuir a su plena inclusión, integración y participación en la sociedad (ONU, 2015, Artículo 1).

Entre los principios generales aplicables a dicha Convención, se establece explícitamente la promoción y defensa de los derechos humanos y libertades fundamentales, la igualdad y no discriminación y la responsabilidad del Estado y participación de la familia y de la comunidad, en la integración activa, plena y productiva de la persona mayor dentro de la sociedad, así como en su cuidado y atención, de acuerdo con su legislación interna.

Esta Convención define claramente a las personas mayores: "Aquella de 60 años o más, salvo que la ley interna determine una edad base menor o mayor, siempre que esta no sea superior a los 65 años. Este concepto incluye, entre otros, el de persona adulta mayor" (Artículo 2). En este caso, la variable a partir de la cual se operacionaliza dicho concepto a través de preguntas en las fuentes de datos, corresponde a la edad cumplida.

\subsubsection{Personas con Discapacidad}

En su Artículo 1, la Convención sobre los Derechos de las Personas con Discapacidad indica que bajo el concepto se incluye a quienes "tengan deficiencias físicas, mentales, intelectuales o sensoriales a largo plazo que, al interactuar con diversas barreras, puedan impedir su participación plena y efectiva en la sociedad, en igualdad de condiciones con las demás" (ONU, 2006, pág. 6).

Para operacionalizar dicho concepto, la referencia consensuada corresponde a la Clasificación Internacional del Funcionamiento, de la Discapacidad y de la Salud (CIF), que define a la discapacidad como

un término genérico que abarca deficiencias, limitaciones de la actividad y restricciones a la participación. Se entiende por discapacidad la interacción entre las personas que padecen alguna enfermedad (por ejemplo, parálisis cerebral, síndrome de Down y depresión) y factores personales y ambientales (por ejemplo, actitudes negativas, transporte y edificios públicos inaccesibles y un apoyo social limitado) (OMS, 2016, pág. 1).

Acorde esta misma Clasificación, la discapacidad puede ocurrir en tres niveles:

- Deficiencia en la función o la estructura corporal, como las cataratas, que impiden el pasaje de la luz y la sensación de la forma y el tamaño de los estímulos

4 La Argentina adhirió oficialmente a dicha Convención con el Decreto 375 de 2015. 
visuales;

- Limitación en la actividad, como la incapacidad de leer o de moverse por sí mismo;

- Restricción de la participación, como la exclusión de la escuela.

Debido a las malinterpretaciones que puede generar dicho concepto en un caso particular, la OMS elaboró también una clasificación específica para los niños, niñas y jóvenes (CIF-NJ), que "considera a la discapacidad no como una cuestión puramente biológica ni puramente social, sino más bien como una interacción entre problemas de salud y factores ambientales y personales" (CIF-NJ; OMS, 2011; citado por OMS/UNICEF, 2013, pág. 7). En este sentido, es importante diferenciar muy bien la discapacidad del retraso:

- Discapacidad:

Algunos niños nacen con una deficiencia o un problema de salud discapacitante, mientras que otros pueden padecer discapacidad como resultado de enfermedades, lesiones o mala nutrición. Los niños con discapacidad incluyen los que tienen afecciones de salud como parálisis cerebral, espina bífida, distrofia muscular, lesión traumática de la médula espinal, síndrome de Down, y niños con deficiencias auditivas, visuales, físicas, comunicacionales e intelectuales. Algunos de estos niños tienen una única deficiencia, mientras que otros tienen varias. Por ejemplo, un niño con parálisis cerebral puede tener deficiencias de movilidad, de comunicación e intelectuales. La compleja interacción entre los problemas o deficiencias de salud y los factores ambientales y personales hace que la experiencia de cada niño frente a la discapacidad sea diferente (OMS/UNICEF, 2013, pág. 7).

- Retraso del desarrollo:

El retraso del desarrollo se refiere a los niños que experimentan una variación significativa en el logro de los pasos esperados para su edad real o ajustada. (...) Aunque es posible que el retraso del desarrollo no sea permanente, puede ofrecer una base para reconocer a los niños que podrían sufrir una discapacidad (OMS/UNICEF, 2013, pág. 12).

Como señala Schkolnik (2011), al operacionalizar el concepto en un censo de población, la variable que debería preponderar, acorde a la CIF, es la correspondiente a la existencia de limitaciones permanentes. No obstante, y al menos en América Latina, es corriente que aún subsistan preguntas censales que utilizan una variable ya en desuso, la existencia de deficiencias. Para la identificación de la disponibilidad de información sobre personas con discapacidad en las fuentes seleccionadas, en este artículo se privilegiará a la modalidad de pregunta basada en la variable limitaciones permanentes.

\subsubsection{Pueblos indígenas}

En los principales instrumentos de derecho internacional referidos a los pueblos indígenas, no existe una definición aceptada de manera unánime. Como señala ACNUDH (2013), en la Declaración de Naciones Unidas sobre los Pueblos Indígenas "en sus artículos 9 y 33 se afirma que los pueblos y los individuos indígenas tienen derecho a pertenecer a una comunidad o nación indígena, de conformidad con las tradiciones y costumbres de la comunidad o nación de que se trate, y a determinar su 
propia identidad" (págs. 2-3). En el Convenio 169 de la Organización Internacional del Trabajo (OIT) sobre pueblos indígenas y tribales en países independientes, Artículo 1 , se establece la siguiente distinción entre pueblos tribales y pueblos indígenas a la vez que se subraya la importancia de la conciencia de la identidad indígena:

1. a) Los pueblos tribales en países independientes, cuyas condiciones sociales, culturales y económicas les distingan de otros sectores de la colectividad nacional, y que estén regidos total o parcialmente por sus propias costumbres o tradiciones o por una legislación especial; b) Los pueblos en países independientes, considerados indígenas por el hecho de descender de poblaciones que habitaban en el país o en una región geográfica a la que pertenece el país en la época de la conquista o la colonización o del establecimiento de las actuales fronteras estatales y que, cualquiera que sea su situación jurídica, conservan todas sus propias instituciones sociales, económicas, culturales y políticas, o parte de ellas. 2. La conciencia de su identidad indígena o tribal deberá considerarse un criterio fundamental para determinar los grupos a los que se aplican las disposiciones del presente Convenio (OIT, 1989, pág. 1).

No obstante la falta de definición conceptual unívoca, la operacionalización en las fuentes sociodemográficas de datos se ha concentrado actualmente, en la autoidentificación; es decir, en la posibilidad de que el respondiente indique su pertenencia o no a la población (¿es, / se considera / pertenece... a algún pueblo indígena?) (Del Popolo, 2008). Actualmente, son muy pocos los países de América Latina y el Caribe, que recurren a otros criterios (como la lengua hablada o nativa). Como menciona el Centro Latinoamericano y Caribeño de Demografía (CELADE, 2009):

En la actualidad, existe consenso internacional acerca de que la forma en que debe obtenerse esta información es mediante una pregunta directa de auto-reconocimiento, lo cual es congruente con el hecho de que los pueblos indígenas constituyen sujetos de derecho. Por tanto se recomienda mantener la línea que han seguido la mayor parte de los países de la región en los censos del 2000, incluyendo en la boleta de la ronda 2010 una pregunta de auto-identificación, aplicable a todas las personas (pág. 19).

\subsubsection{Afrodescendientes}

Con relación a la definición de afrodescendiente, existe un importante consenso en que corresponde a todos los pueblos y personas descendientes de la diáspora africana en el mundo (Sánchez, 2007). En nuestra región, el concepto alude "a las distintas culturas negras y afroamericanas que emergieron de los descendientes de africanos, y sobrevivieron a la trata y al comercio esclavista que se dio en el Atlántico entre los siglos XVI y XIX" (Antón y Del Popolo, 2009, pág. 20).

En cuanto al criterio de clasificación y de manera similar a lo observado para los pueblos indígenas, "se recomienda a los países que mantengan la autoidentificación. Cabe señalar, que la clasificación propiamente tal utilizada por los países responde, en general, a categorías étnico-raciales, en el sentido de una construcción social basada en el fenotipo" (CELADE, 2009, pág. 21).

\subsubsection{Migrante internacional (y sus familiares)}

Con respecto a la definición de migrante, en materia de derecho internacional no existe una definición universalmente aceptada. Como sintetiza la Organización 
Internacional para las Migraciones (OIM, 2017):

Este término abarca usualmente todos los casos en los que la decisión de migrar es tomada libremente por la persona concernida por 'razones de conveniencia personal' y sin intervención de factores externos que le obliguen a ello. Así, este término se aplica a las personas y a sus familiares que van a otro país o región con miras a mejorar sus condiciones sociales y materiales y sus perspectivas y las de sus familias (pág. 1).

En términos de operacionalización, el concepto implica la identificación del país de nacimiento y el cambio de residencia (internacional), y la determinación de las relaciones de parentesco con el jefe del hogar (al menos, respecto a las personas que lo acompañan en dicho cambio de residencia).

\subsubsection{Refugiado}

El Alto Comisionado de las Naciones Unidas para los Refugiados (ACNUR, 2017), destaca que:

De acuerdo con la Convención de Ginebra sobre el Estatuto de los Refugiados, un refugiado es una persona que debido a fundados temores de ser perseguida por motivos de raza, religión, nacionalidad, pertenencia a un determinado grupo social u opiniones políticas, se encuentre fuera del país de su nacionalidad y no pueda 0 , a causa de dichos temores, no quiera acogerse a la protección de su país; o que careciendo de nacionalidad y hallándose, a consecuencia de tales acontecimientos fuera del país donde antes tuviera su residencia habitual, no pueda o, a causa de dichos temores no quiera regresar a él (pág. 1).

Este mismo organismo proporciona una importante pista para la operacionalización del concepto, al establecer su diferencia respecto al "migrante económico":

Normalmente, un migrante abandona su país voluntariamente, en busca de una vida mejor. Para un refugiado, las condiciones económicas del país de asilo son menos importantes que su seguridad. En la práctica, la distinción puede ser, en ocasiones, difícil de establecer, pero es fundamental: un migrante disfruta de la protección del gobierno de su país de origen, el refugiado no (ACNUR, 2017, pág. 1).

En este sentido, la figura del refugiado se operacionaliza de manera similar al de una migración forzada, no buscada por quien la protagoniza.

\subsection{Disponibilidad de las variables en fuentes de datos}

En la Tabla 1 se presentan los resultados obtenidos, en lo que respecta a la identificación, en cada una de las fuentes de datos seleccionadas, de las variables que permiten la operacionalización de las poblaciones en situación de vulnerabilidad social (gris claro: disponible, gris oscuro: disponible por aproximación, negro: no disponible, blanco: no corresponde/no aplica).

Como se aprecia, las posibilidades de las fuentes de datos analizadas para la identificación de poblaciones en situación de vulnerabilidad social, varían fuertemente de un caso a otro. Las mujeres por ejemplo, pueden ser identificadas a partir de la variable sexo en todas las fuentes de datos, independientemente del tipo de relevamiento y de su momento de producción.

En el caso de los niños -menores de 18 años acorde diferentes subgrupos-, se supondría que podrían ser reconocidos en todas las fuentes ya que la edad constituye 
una variable tan básica como la variable sexo. Sin embargo, la identificación es posible sólo en los censos de población considerados y en encuestas que involucran específicamente a todas o gran parte de las etapas del ciclo vital (para el caso por ejemplo, EDS y ECV). En el resto de las encuestas se incluye a esta misma variable, pero se observan diferentes situaciones que restringen la identificación: a) se trata de encuestas (o módulos dentro de una encuesta) que indagan solo algunas de las edades que involucran a la niñez (por ejemplo, el módulo de Monitoreo de Metas sociales incluido en la EPH puntual de 1994-5, que posee cuestionarios para menores de 6 años y de 6 a 14 años, pero no para los mayores de esa edad que no cumplieron 18 años), b) que poseen otras poblaciones objetivo que rara vez contienen todos los segmentos de edad incluidos en la definición de "niñez" (por ejemplo, la EPH continua que limita el cuestionario individual a la población de 10 años y más), o c), que directamente excluyen a los niños (como la ENFR, aplicada para población de 18 y más años).

Con relación a las personas mayores, se observa una gran inclusión en las fuentes de datos seleccionadas. Esta situación se relaciona también, con la corriente inclusión de la variable utilizada para la operacionalización de esta población en situación de vulnerabilidad social; es decir, la edad cumplida.

Las excepciones están representadas por las encuestas que no aplican respecto a dicha población (módulo sobre salud materno-infantil de EPH-1994, y módulos o encuestas MANNyA). Sin embargo, sorprende la imposibilidad de caracterizar a esta población a partir de la ENSSyR del año 2013, ya que la misma se aplica a mujeres de 14 a 49 años y hombres de 14 a 59 años. Se advierte, además, que la identificación de los adultos mayores en algunas fuentes de datos no garantiza una cobertura temática adecuada. Este es el caso de los censos en instituciones o viviendas colectivas (2001 y 2010):

no existe aproximación posible de la condición étnica de los ancianos en ambos censos (ya que la pregunta que permitiría un proxy del indicador se capta exclusiva y necesariamente en los hogares particulares), ni sobre estado civil y educación en el relevamiento del año 2010 (debido a que el formulario aplicado en viviendas colectivas incluía solamente las preguntas básicas) (Ribotta, Pizarro, Santillán Paredes y Peláez, 2014, pág. 11). 


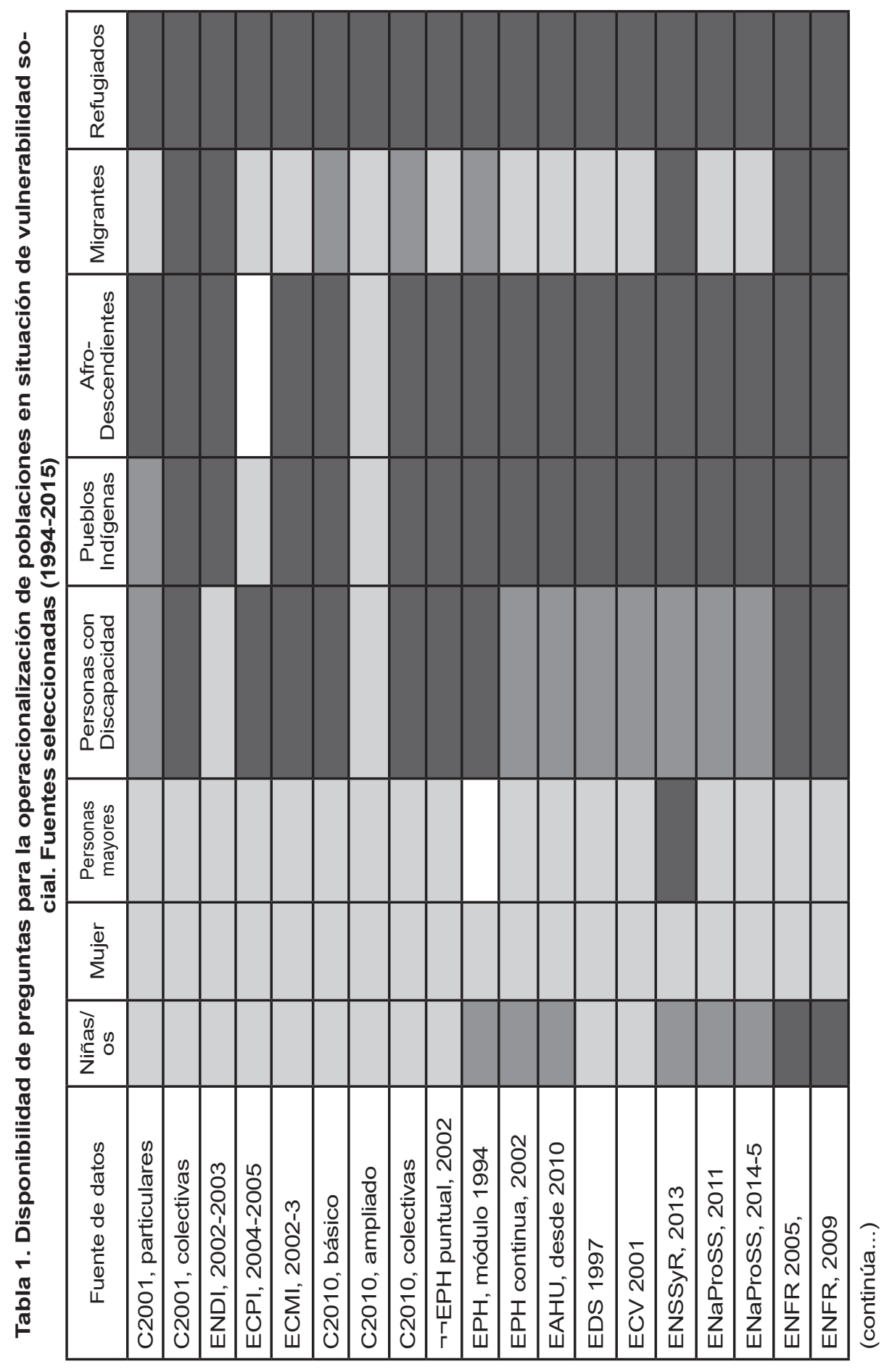




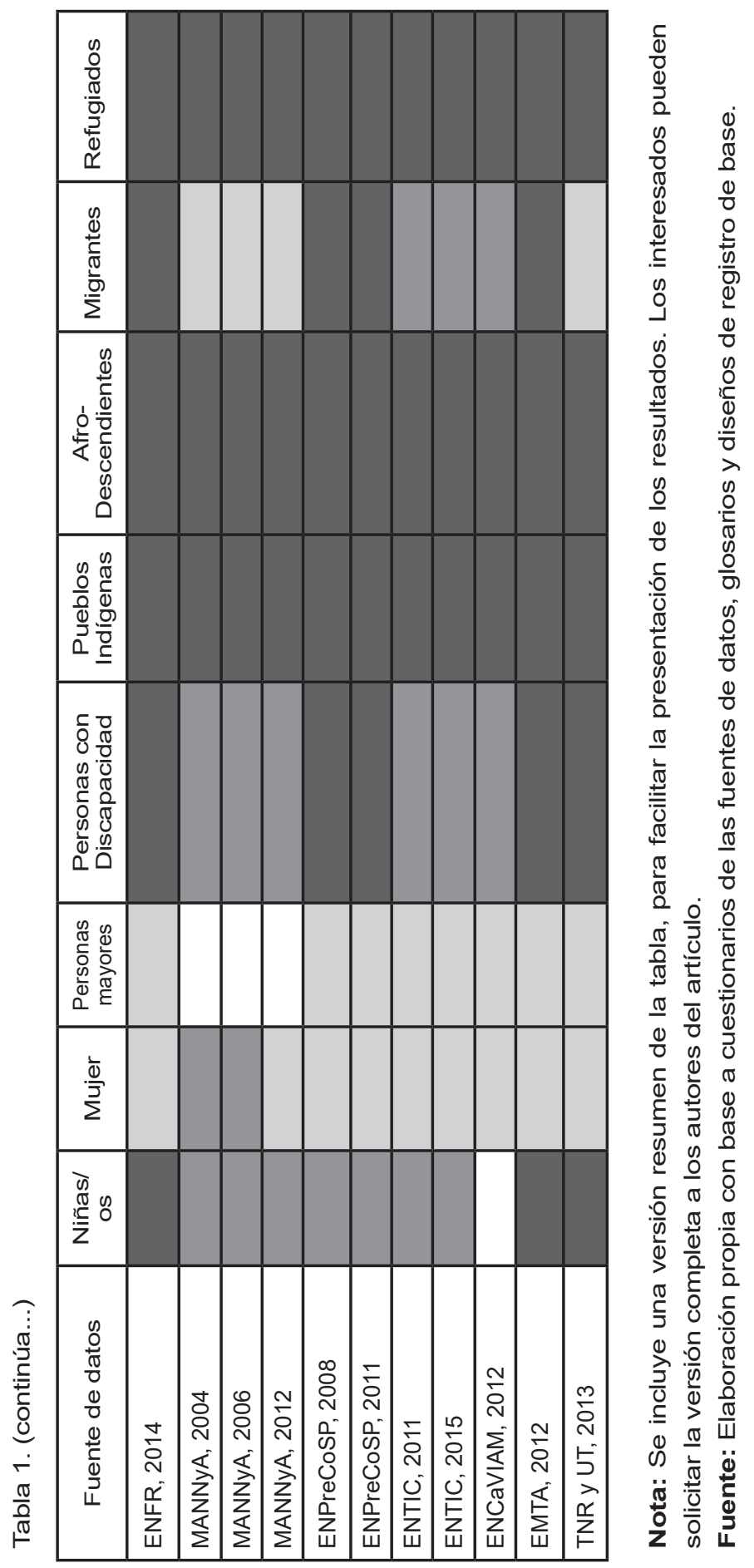

SAberEs. Vol. 12, Núm.1 (2020). 45-71. Sección ARticulos 
En cuanto a las personas con discapacidad, nuevamente los censos y sus encuestas complementarias son las fuentes de datos que realizan una mejor identificación. En especial, merece destacarse la ENDI 2002-2003 y el Censo 2010 (formulario ampliado). En otras fuentes de datos, la incorporación de dicha variable de desagregación cambia acorde el tiempo (escaso desarrollo conceptual y operacional, como muestra la EDS), a formas de especificación incompletas y muy cambiantes en las encuestas más actuales (preguntas directas y parciales -como las consultas por la existencia del certificado de discapacidad, que podría brindar una aproximación), hasta su inexistencia. Llama la atención que en la encuesta dedicada a determinar las condiciones de vida de los adultos mayores (ENCaVIAM, 2012), se indaguen sólo ciertos casos puntuales de deficiencia.

Sólo muy pocas fuentes de datos permiten identificar a la población integrante de pueblos indígenas y a los afrodescendientes. En el primer caso se trata del censo 2001 a nivel hogar, de su encuesta complementaria ECPI 2004-2005, y del Censo 2010 (cuestionario ampliado). Este último relevamiento es el único que hasta la fecha contempla a los afrodescendientes.

Finalmente, puede observarse que muchas fuentes de datos permiten identificar al menos de una manera básica, a los migrantes internacionales y sus familiares. Por el contrario, ninguna permite hacer lo mismo con los refugiados.

\subsection{Características de las fuentes de datos}

En la Tabla 2, se muestra una selección de características de las fuentes de datos, cuyo análisis resulta particularmente importante para apreciar las posibilidades de monitorear el ejercicio de derechos en poblaciones en situación de vulnerabilidad social. Se hace alusión muy especialmente a la posibilidad de contar con estimaciones representativas en su cobertura geográfica, que permitan estimaciones de precisión, y su apreciación comparativa a lo largo del tiempo. 


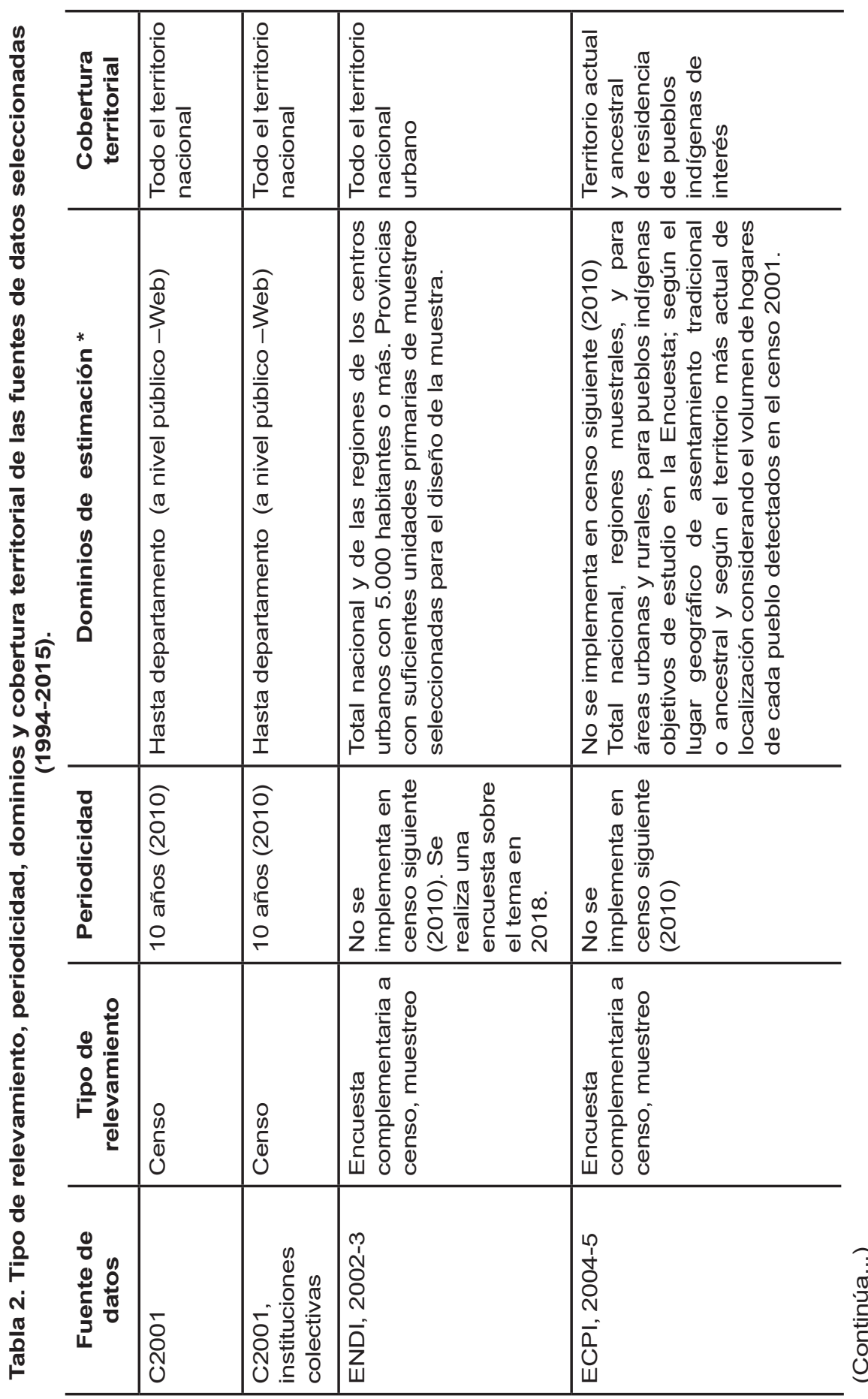

SAberEs. Vol. 12, Núm.1 (2020). 45-71. Sección ARticulos 


\begin{tabular}{|c|c|c|c|c|c|}
\hline 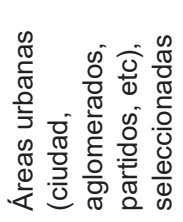 & 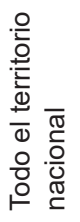 & 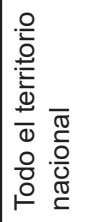 & 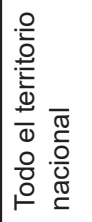 & 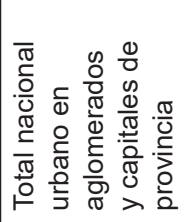 & 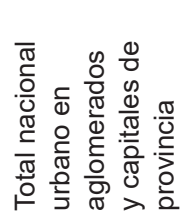 \\
\hline 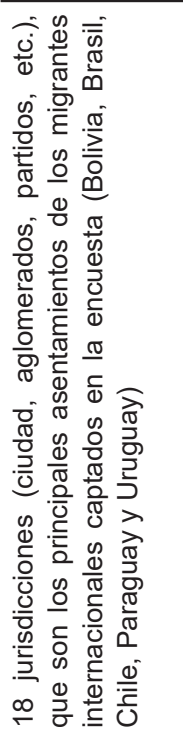 & 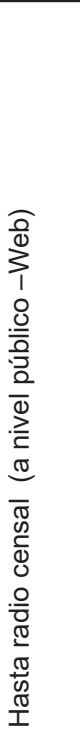 & 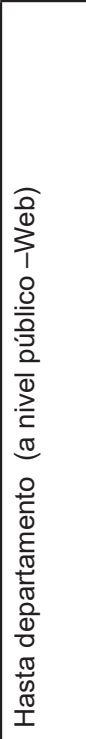 & 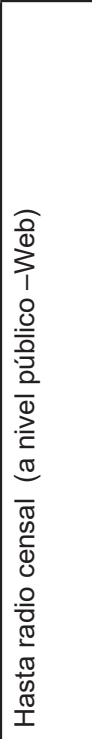 & 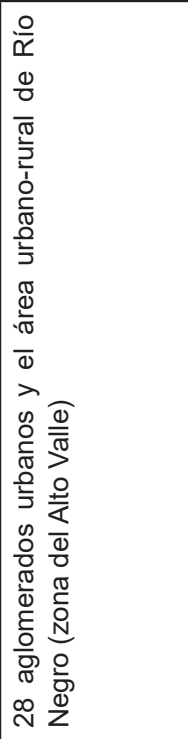 & 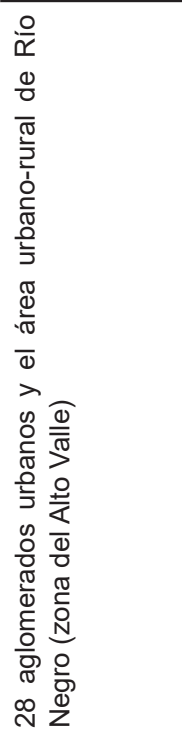 \\
\hline 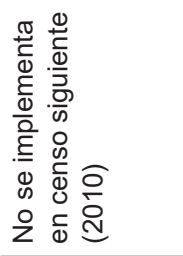 & 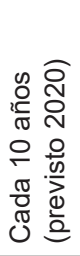 & 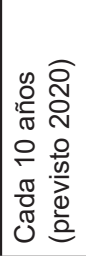 & 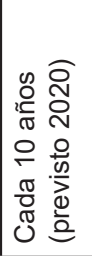 & 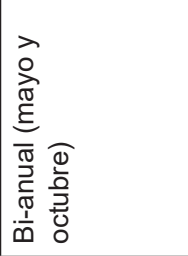 & 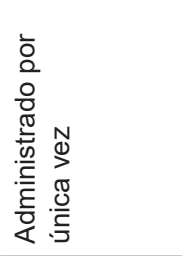 \\
\hline 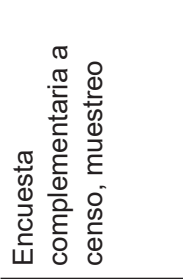 & 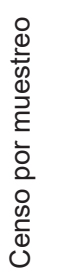 & 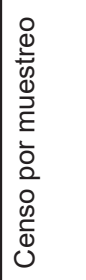 & 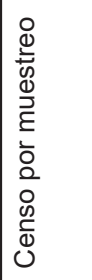 & 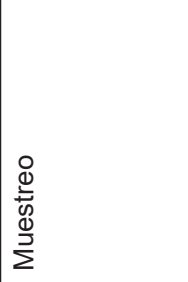 & 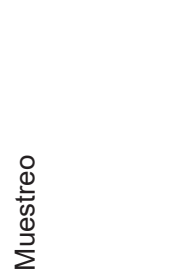 \\
\hline 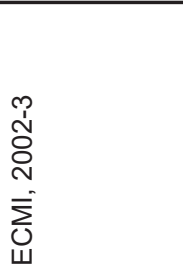 & 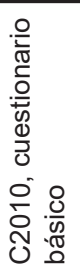 & 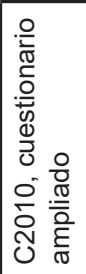 & 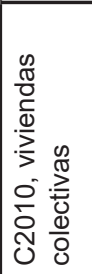 & 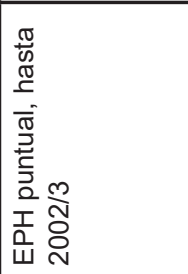 & 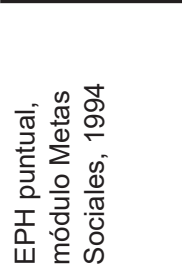 \\
\hline
\end{tabular}




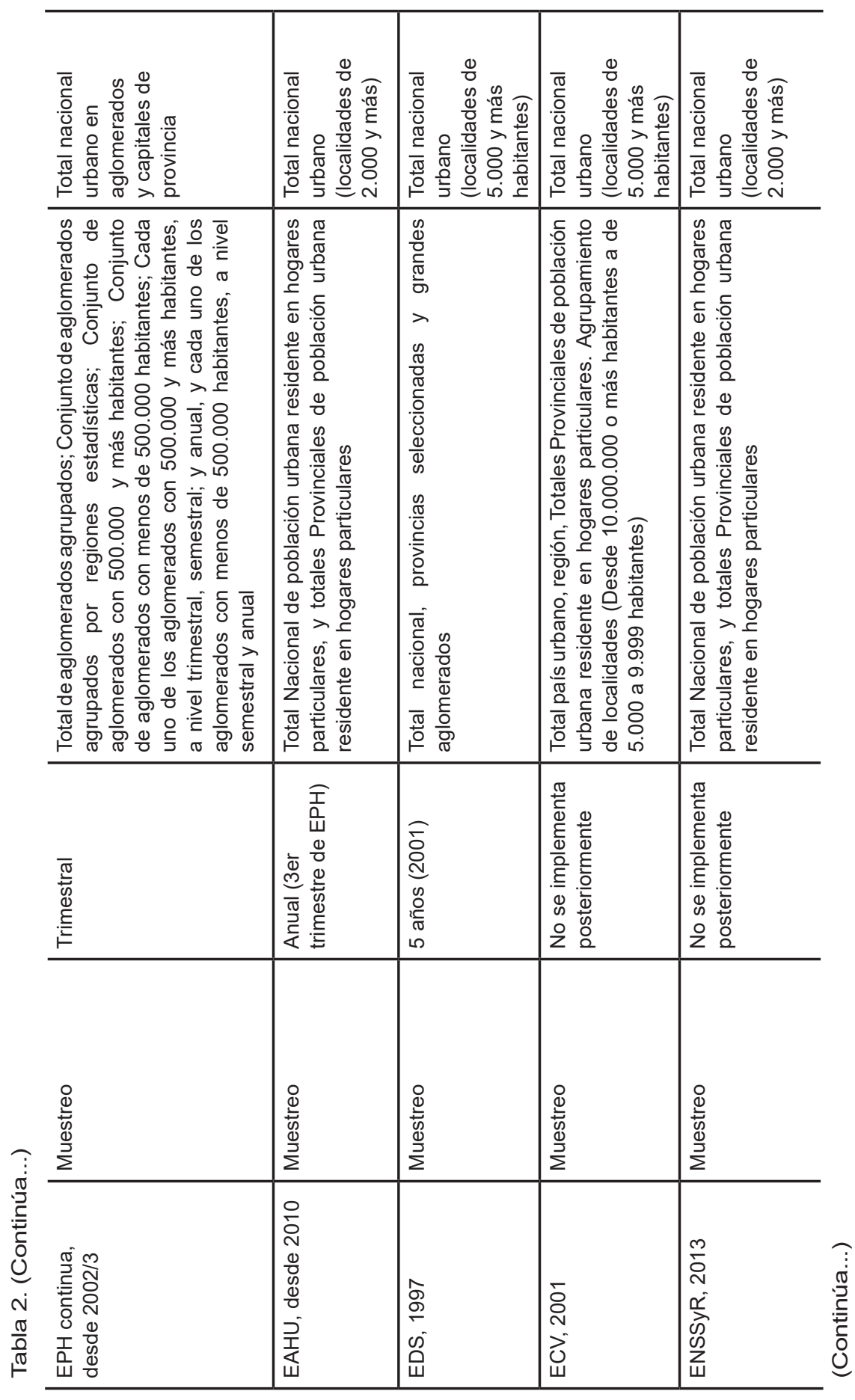




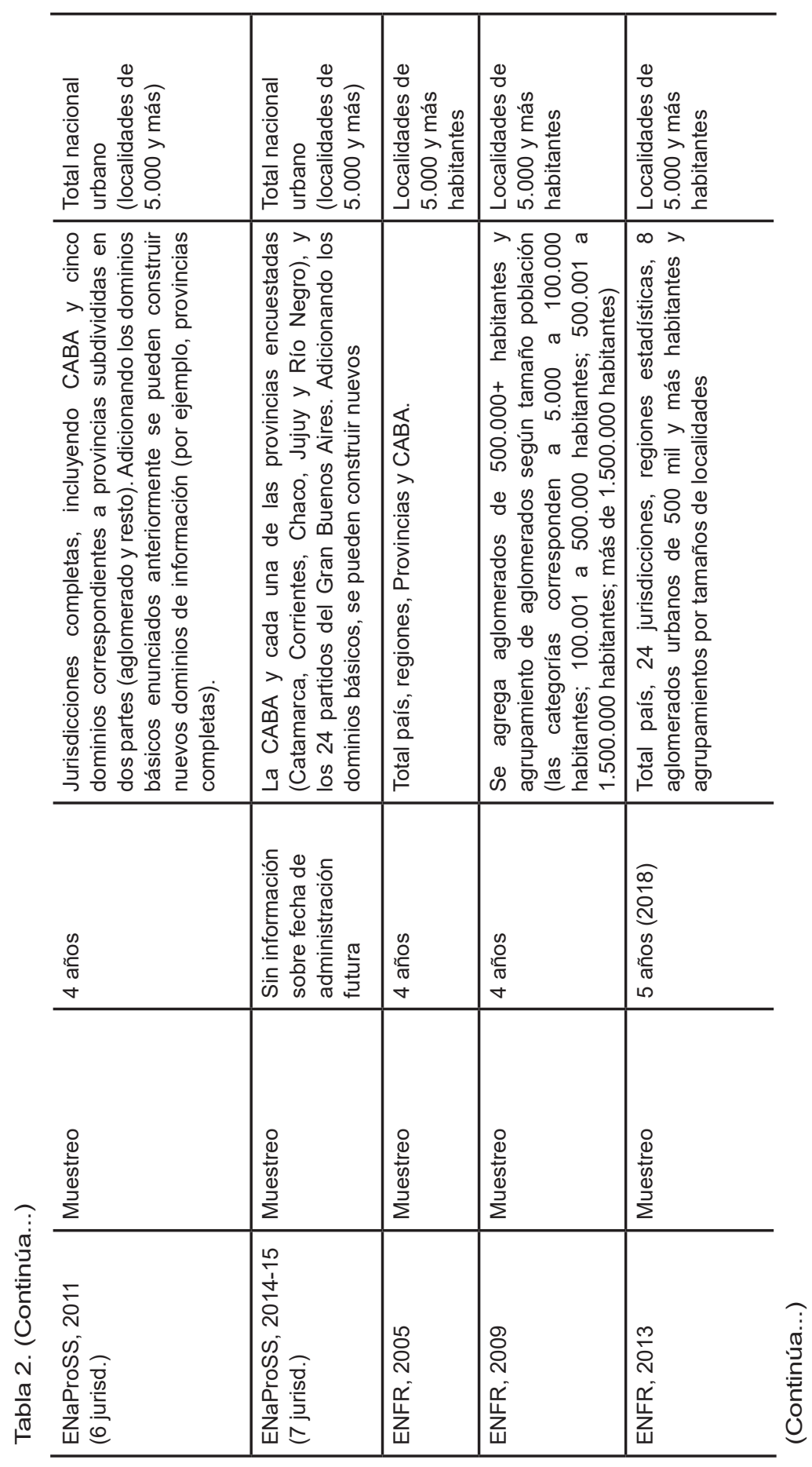




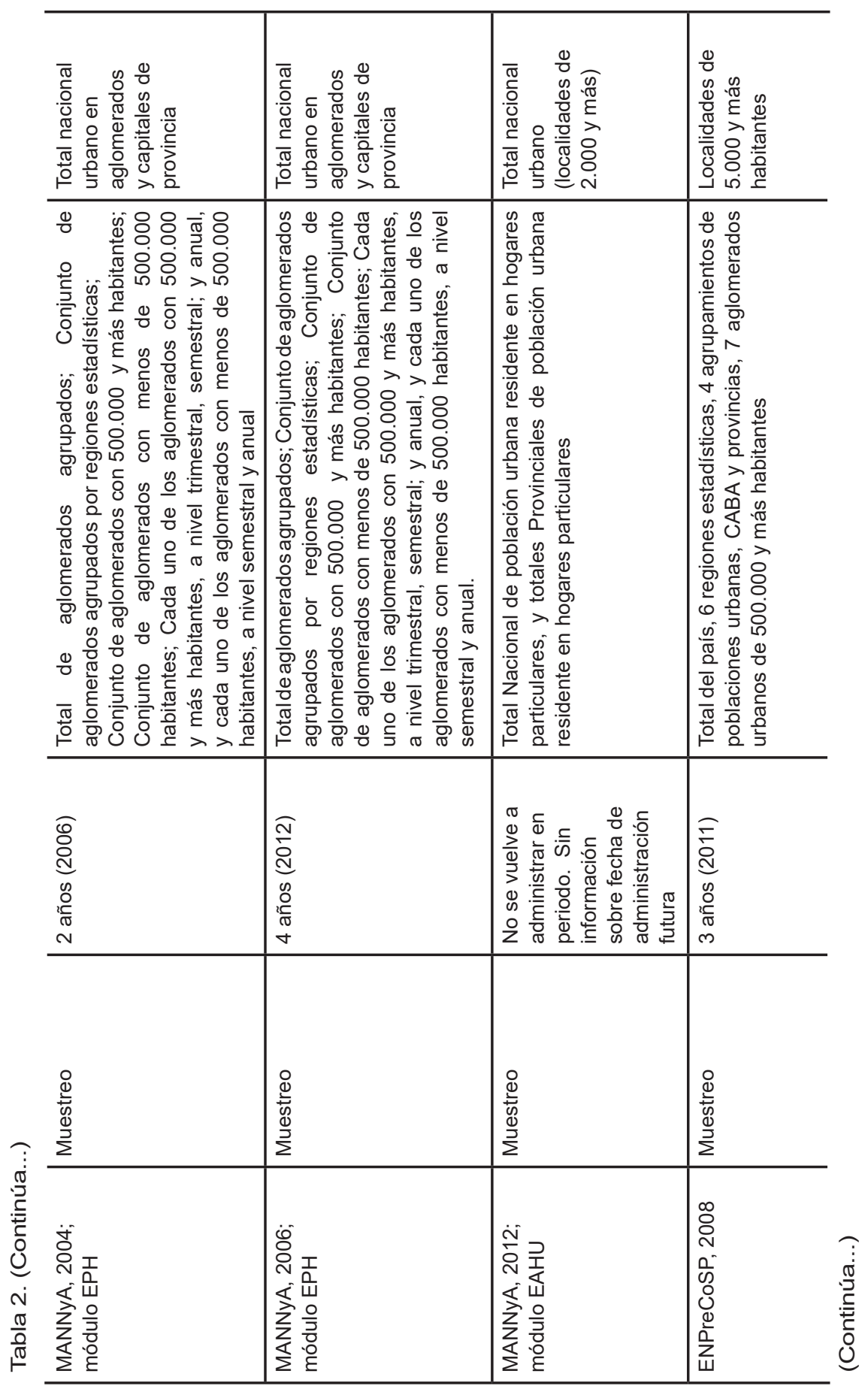




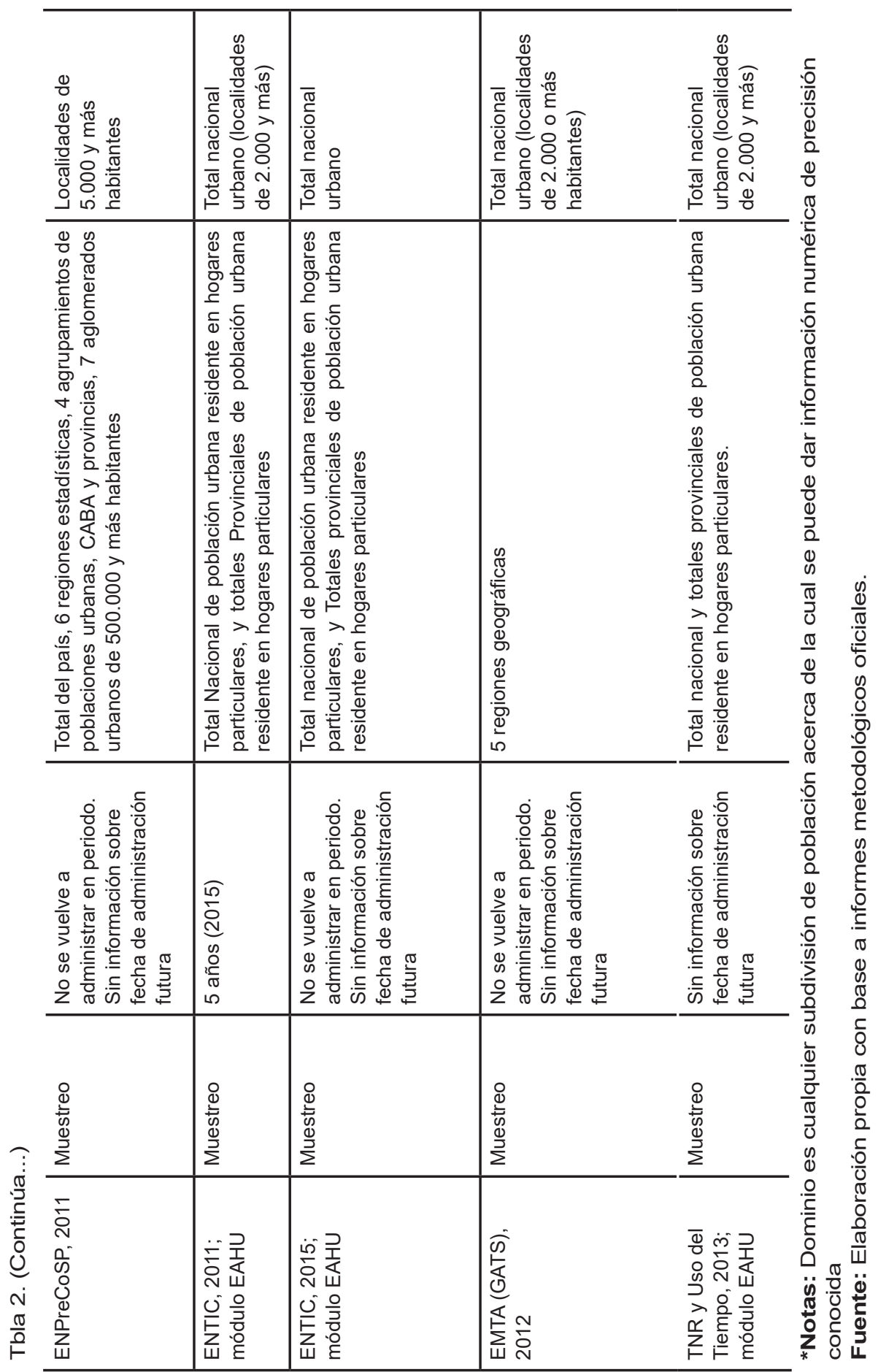


Como se aprecia, son principalmente dos las pautas que distinguen a unas fuentes de otras: a) por un lado, los censos de población que cuentan con dominios de estimación amplios y de cobertura geográfica muy representativa y que, no obstante, poseen escasa periodicidad. En cuanto al ejercicio de los derechos de las poblaciones en situación de vulnerabilidad social, las primeras ventajas se contrarrestan en parte por la segunda circunstancia, ya que los cambios solo pueden ser apreciados en lapsos demasiado amplios; b) por otro lado, las encuestas de hogar que permiten un seguimiento de alta periodicidad en el tiempo, aunque con pérdida de cobertura geográfica (todas son fuentes de población urbana, aunque en el mejor caso incluyendo hasta localidades de 5.000 y 2.000 habitantes), y en los dominios de estimación. En este conjunto, las mejor posicionadas son las encuestas de hogar (EPH, EAUH), aunque como es bien sabido, poseen las mayores limitaciones de contenido. Una circunstancia llamativa es la interrupción de la periodicidad de algunas de estas encuestas (como la EDS y ECV, que se encontraban emparentadas), o la existencia de otros relevamientos específicos -o módulos dentro de otras encuestas-, que no han vuelto a replicarse en el tiempo (tal es el caso de la ENSSyR, ENCaViAM, ENPreCoSP, MANNyA, etc. $)^{5}$.

\section{Conclusiones}

El presente trabajo permitió una aproximación al diagnóstico de la disponibilidad y de las características metodológicas más generales de las fuentes de información seleccionadas, para identificar poblaciones en situación de vulnerabilidad social. Los hallazgos permiten la realización de recomendaciones para mejorar las fuentes de información existentes y desarrollar nuevos instrumentos oficiales de recolección de datos.

Se advierte que si bien hay una gran cantidad de fuentes de datos socio-demográficos oficiales en la Argentina, no todas posibilitan la identificación de poblaciones en situación de vulnerabilidad social. Es muy notable el déficit que al respecto existe, para la delimitación de las personas afrodescendientes o pertenecientes a pueblos indígenas, y mucho más de los refugiados (categoría que en realidad debería ser más estudiada, y en todo caso, contemplada mediante otros instrumentos de recolección de datos, como los registros).

En cuanto a las fuentes de datos en particular, los censos sobresalen por su cobertura geográfica pero no así por su periodicidad. También se caracteriza por ser la fuente que permite identificar a todas las poblaciones consideradas en situación de vulnerabilidad social en este artículo, a excepción de las personas refugiadas. Otras fuentes de datos sociodemográficas, como las encuestas de hogares o de temáticas específicas, no cuentan con las variables necesarias para identificar a gran parte de estas poblaciones 0 , aún cuando las variables están presentes, no siempre son captadas de la misma (o de forma integrada), lo que limitaría la posibilidad de su seguimiento a lo largo del tiempo, condición necesaria para evaluar/monitorear

\footnotetext{
5 Cabe destacar que dicha situación se mantiene incluso hasta la actualidad. A la fecha, desde 2015 se mantuvieron los censos y encuestas de hogar (EPH-EAHU), las encuestas ENTIC y ENFR, y se crearon muy pocas relevamientos nuevos (Encuesta sobre Victimación en 2017, Encuesta Perfil de Personas con Discapacidad en 2018).
} 
tendencias.

Estos primeros hallazgos resaltan la necesidad de seguir profundizando el diagnóstico de la situación actual y, teniendo en cuenta que las fuentes de datos existentes no fueron pensadas desde una perspectiva de derechos, resulta necesario proponer estrategias para complementar las fuentes existentes, o definir situaciones que requieren diseñar nuevas formas de recopilar información. A su vez, es preocupante que algunas encuestas, muy valiosas para la caracterización de las poblaciones en situación de vulnerabilidad social, no fueron replicadas con el paso del tiempo, ni siquiera tampoco fuera del periodo estudiado.

\section{Referencias bibliográficas}

ACNUDH [Alto Comisionado de las Naciones Unidas para los Derechos Humanos]. (2008). Informe sobre los Indicadores para Promover y Vigilar el Ejercicio de los Derechos Humanos. Ginebra, Suiza: Naciones Unidas.

ACNUDH [Alto Comisionado de las Naciones Unidas para los Derechos Humanos]. (2012). Indicadores de derechos humanos. Guía para la medición y la aplicación. Nueva York, EEUU y Ginebra, Suiza: Naciones Unidas.

ACNUDH [Alto Comisionado de las Naciones Unidas para los Derechos Humanos]. (2015). ¿Qué son los derechos humanos? Recuperado de: http://www.ohchr. org/SP/Issues/Pages/WhatareHumanRights.aspx

ACNUDH [Alto Comisionado de las Naciones Unidas para los Derechos Humanos]. (2013). Los pueblos indígenas y el sistema de derechos humanos de las Naciones Unidas. Nueva York, EEUU: Naciones Unidas.

ACNUDH [Alto Comisionado de las Naciones Unidas para los Derechos Humanos]. (2017). ¿Quién es un Refugiado? Recuperado de: http://www.acnur.org/aquien-ayuda/refugiados/quien-es-un-refugiado/

ACNUDH [Alto Comisionado de las Naciones Unidas para los Derechos Humanos]. (2017). Los Instrumentos Universales de los derechos humanos. Recuperado de: http://www.ohchr.org/SP/Professionallnterest/Pages/ UniversalHumanRightsInstruments.aspx

Antón, J. y Del Popolo, F. (2009). Visibilidad estadística de la población afrodescendiente de América Latina: aspectos conceptuales y metodológicos. En Antón, J., Bello, A., Del Popolo, F., Paixao, M. y Rangel, M. (Comps.), Afrodescendientes en América Latina y el Caribe: del reconocimiento estadístico a la realización de derechos. Santiago, Chile: CEPAL.

Busso, G. (2001). Vulnerabilidad social: nociones e implicancias de políticas para Latinoamérica a inicios del siglo XXI. Santiago, Chile: CEPAL.

Castel, R. (1997). Las metamorfosis de la cuestión social. Una crónica del asalariado. Buenos Aires, Argentina: Paidós.

CELADE [Centro Latinoamericano y Caribeño de Demografía]. (2009). 
Recomendaciones para los censos de 2010 sobre cartografía censal, migraciones, enfoque étnico y cobertura censal. Santiago, Chile: CEPAL.

CEPAL [Comisión Económica para América Latina y el Caribe]. (2001). Vulnerabilidad sociodemográfica: viejos y nuevos riesgos para comunidades, hogares y personas. Santiago, Chile: CEPAL.

Cutter, S. (1996). Vulnerability to environmental hazards. Progress in Human Geography, 20(4), pp. 529-539.

Del Popolo F. (2008). Los pueblos indígenas y afrodescendientes en las fuentes de datos: experiencias en América Latina. Santiago, Chile: CEPAL/CELADE.

Ferrer, M. (2007) Derechos humanos en población: indicadores para un sistema de monitoreo. Santiago, Chile: CELADE/CEPAL.

Kaztman, R. (1999). Activos y estructuras de oportunidades. Estudios sobre las raíces de la vulnerabilidad social en Uruguay. Montevideo, Uruguay: CEPAL.

OIM [Organización Internacional para las Migraciones]. (2017). Los términos clave de migración. Recuperado de: http://www.iom.int/es/los-terminos-clave-demigracion

OIT [Organización Internacional del Trabajo]. (1989). Convenio sobre pueblos indígenas y tribales en países independientes (Entrada en vigor: 05 septiembre 1991). ORMLEXPUB:12100:0::NO::P12100_ILO_CODE:C169

OMS [Organización Mundial de la Salud] / UNICEF [Fondo de las Naciones Unidas para la Infancia]. (2013). El desarrollo del niño en la primera infancia y la discapacidad: un documento de debate. Ginebra, Suiza: OMS.

OMS [Organización Mundial de la Salud]. (2016). Discapacidad y salud. Recuperado de: http://www.who.int/es/news-room/fact-sheets/detail/disability-and-health

ONU Mujeres [Entidad de la ONU para la Igualdad de Género y el Empoderamiento de la Mujer]. (2014). Glosario de Igualdad de Género. Recuperado de: https://trainingcentre.unwomen.org $/ \mathrm{mod} /$ glossary $/$ view. php?id=150\&mode=I etter\&hook $=\mathrm{E} \&$ sortkey $=$ \&sortorder $=$ asc

ONU [Organización de las Naciones Unidas]. (1951). Convención sobre el Estatuto de los Refugiados. Adoptada en Ginebra, Suiza, el 28 de julio de 1951 por la Conferencia de Plenipotenciarios sobre el Estatuto de los Refugiados y de los Apátridas (Naciones Unidas), convocada por la Asamblea General en su resolución 429 (V), del 14 de diciembre de 1950. Entrada en vigor: 22 de abril de 1954. Recuperado de: http://www.acnur.org/fileadmin/scripts/doc. php?file=fileadmin/documentos/bdl/2001/0005

ONU [Organización de las Naciones Unidas]. (1965). Convención Internacional sobre la Eliminación de todas las formas de Discriminación Racial. Adoptada y abierta a la firma y ratificación por la Asamblea General en su resolución 2106 A (XX), de 21 de diciembre de 1965. Entrada en vigor: 4 de enero de 
1969, de conformidad con el artículo 19. Recuperado de: http://www.ohchr. org/SP/Professionallnterest/Pages/CERD.aspx

ONU [Organización de las Naciones Unidas]. (1979). Convención sobre la Eliminación de todas las formas de Discriminación contra la Mujer. Adoptada y abierta a la firma y ratificación, o adhesión, por la Asamblea General en su resolución 34/180, de 18 de diciembre de 1979. Entrada en vigor: 3 de septiembre de 1981, de conformidad con el artículo 27 (1). Recuperado de: http://www. ohchr.org/SP/Professionallnterest/Pages/CEDAW.aspx

ONU [Organización de las Naciones Unidas]. (1989). Convención sobre los Derechos del Niño. Adoptada y abierta a la firma y ratificación por la Asamblea General en su resolución 44/25, de 20 de noviembre de 1989. Entrada en vigor: 2 de septiembre de 1990, de conformidad con el artículo 49. Recuperado de: http://www.ohchr.org/SP/Professionallnterest/Pages/CRC.aspx

ONU [Organización de las Naciones Unidas]. (1990). Convención Internacional sobre la Protección de los Derechos de todos los Trabajadores Migratorios y de sus Familiares. Adoptada por la Asamblea General en su resolución 45/158, de 18 de diciembre de 1990. Recuperado de: http://www.ohchr.org/ SP/Professionallnterest/Pages/CMW.aspx

ONU [Organización de las Naciones Unidas]. (2006). Convención sobre los Derechos de las Personas con Discapacidad y su Protocolo Facultativo. Aprobados el 13 de diciembre de 2006 en la Sede de las Naciones Unidas en Nueva York, y abiertos a la firma el 30 de marzo de 2007. Recuperado de: http://www. un.org/disabilities/documents/convention/convoptprot-s.pdf

ONU [Organización de las Naciones Unidas]. (2015). Transformar nuestro mundo: la Agenda 2030 para el Desarrollo Sostenible. Nueva York, Naciones Unidas, Resolución aprobada por la Asamblea General el 25 de septiembre de 2015. Recuperado de: https://unctad.org/meetings/es/SessionalDocuments/ ares70d1_es.pdf

Pemberton, S., Gordon, D. y Nandy, S. (2012). Child rights, child survival and child poverty: the debate. En Minujin, A. y Nandy, S. (Eds.), Global Child Poverty and Well-Being. Measurement, concepts, policy and action. Bristol, Inglaterra: The Policy Press. Recuperado de: https://www.cssquest.com/wp-content/ uploads/2017/09/Global-Child-Poverty-and-Well-Being.pdf\#page=52

República Argentina. ([1994] 2010). Constitución de la Nación Argentina: Publicación del Bicentenario. Buenos Aires, Argentina: Corte Suprema de Justicia de la Nación, Biblioteca del Congreso de la Nación, Biblioteca Nacional.

Ribotta, B., Santillán Pizarro, M. M., Paredes, M. y Peláez, E. (2014). Adultos mayores y monitoreo de derechos. Alcances y limitaciones de las fuentes de información en Argentina y Uruguay. Revista Población y Salud en Mesoamérica, 11(2): pp. 1-47. 
SITEAL [Sistema de Información de Tendencias Educativas en América Latina]. (2010). Sistema de Información sobre los Derechos del Niño en la Primera Infancia en los países de América Latina Marco teórico y metodológico. Buenos Aires, Argentina: IIPE - UNESCO.

Schkolnik, S. (2011). América Latina: la medición de la discapacidad a partir de los censos y fuentes alternativas. Notas de Población, 94: pp. 275-305.

UNICEF [Fondo de las Naciones Unidas para la Infancia]. (2011). Estado Mundial de la Infancia de 2011. La adolescencia: una época de oportunidades. Ginebra, Suiza: UNICEF. 